\title{
Quicker Measurement of Walls' Thermal Resistance Following an Extension to ISO 9869 Average Method
}

\author{
Arash Rasooli ${ }^{1, *}$, Laure $_{\text {Itard }}{ }^{1}$ \\ ${ }^{1}$ OTB: Research for the Built Environment, Delft University of Technology, Julianalaan 134, Delft, the Netherlands
}

\begin{abstract}
Determination of the thermo-physical characteristics of the buildings' components is crucial to illustrate their thermal behavior and therefore their energy consumption. Along the same line, accurate determination of the thermal resistance of the building walls falls into one the most important targets. Following the difference between in-lab, and on site thermal performance of walls, in-situ measurements have been highly recommended. The most well-known practice for in-situ measurement of walls' thermal resistance is the Average Method of ISO 9869, using one heat flux meter and two thermocouples. The method, in comparison with other existing methods is quite straight-forward and therefore, is applied widely in large scale. Despite its simplicity, this method usually needs a relatively long time to reach an acceptable result. The current paper deals with a modification to the ISO 9869 method, making it in many situations much quicker than its original state. Through simulation of walls of different typologies, it is shown in which cases the measurement period becomes longer than expected. It is demonstrated how the addition of a heat flux meter to the aforementioned equipment can lead to a much quicker achievement of the thermal resistance, following the rest of the instructions of the standard method.
\end{abstract}

\section{Introduction}

Thermal resistance of the buildings' exterior walls is a key parameter to determine the thermal behavior of the whole building as well as its energy demand. As a result, numerous researches and studies have been dedicated to this area, to measure and validate the correct thermal resistance $\mathrm{R}_{\mathrm{c}}$-value of the existing walls. Efforts have been made to improve the stability, robustness, and accuracy of the results of $\mathrm{R}_{\mathrm{c}}$-values and other thermophysical characteristics of walls [1-4]. Besides the In-lab methods [5-9], In-situ methods [10-15] have been of a higher preference due to the well-known difference in the walls' thermal performance in controlled (e.g. in-lab) conditions vs actual climatic (in-situ) conditions. The insitu conditions including large temperature drifts [16] and wind velocity [17] make a significant difference in the results of heat flux and temperature measurements. Along the same line, ISO 9889 [12], ASTM 1155-95 [11], and 1046 [10] standards have been developed and applied widely $[13,14,18,19]$ to measure this parameter in-situ with a quite straight forward procedure. The specific method being used in large scale campaigns [18, $20]$ is the "Average Method" by ISO 9869 [12], referred to as "Summation Method" in ASTM [10, 11]. The method is based on the definition of the long-term average (cumulative) $\mathrm{R}_{\mathrm{c}}$-value. In this method, the heat flux at one side (indoor side due to a more stable temperature) and the surface temperature at two sides of a wall are monitored for a relatively long period of time.
Accordingly, the average thermal resistance can then be determined as follows:

$$
R_{c}=\sum_{t=0}^{m} \Delta T^{t} / \sum_{t=0}^{m} \dot{q}^{t}
$$

Where $\Delta T$ is the temperature gradient of the two sides, $\dot{q}$ is the heat flux, measured at one side (usually indoor), and $t$ is time. The index $m$ is the minimum number of time intervals (e.g. one hour) required to fulfill the criteria for reporting the $\mathrm{R}_{\mathrm{c}}$-value. The magnitude of this number (duration of the measurement) is a well-known practical obstacle [18] associated with the method. Measuring the heat flux and temperature profiles, an $\mathrm{R}_{\mathrm{c}}$ value is generated at every time interval (typically $0.5 \mathrm{~h}$ to $1 \mathrm{~h}$ ). The cumulative $\mathrm{R}_{\mathrm{c}}$-value profile converges within time, and, may be reported if the following criteria [12] are fulfilled:

1- Minimum duration of $72 \mathrm{~h}$ for the measurements.

2- The loggings are the average of the measurements of shorter intervals.

3- The departure of the two last $\mathrm{R}_{\mathrm{c}}$-values are within $5 \%$. 4- The analysis of last and first certain days results in two $\mathrm{R}_{\mathrm{c}}$-values which do not differ by more than $5 \%$.

Generally, in unstable climatic conditions and high thermal mass, the above criteria are fulfilled hardly or at a considerably late time. As a result, the duration of the measurement becomes too long and therefore

Corresponding author: A.Rasooli@tudelft.nl 
problematic in practice. In this study, an extension [21] to the ISO 9869 [12] method is investigated, to shorten the aforementioned measurement time. The effect of using a second heat flux meter at the opposite side of the wall (Fig. 1), on the required measurement duration is illustrated. The proposed extension is based on the conservation of energy, and therefore, the fact that the sums of the cumulative heat fluxes at two sides of the wall are equal in long term:

$$
\sum_{t=0}^{m}\left(\dot{q}^{t}\right)_{1}=\sum_{t=0}^{m}\left(\dot{q}^{t}\right)_{2}
$$

Accordingly, there is always a point in time where the cumulative $\mathrm{R}_{\mathrm{c}}$-value is the same if either of the sides is chosen for the measurement of the heat flux. Then:

$$
R_{c 1}=\frac{\sum_{t=0}^{m} \Delta T^{t}}{\sum_{t=0}^{m}\left(\dot{q}^{t}\right)_{1}}=R_{c 2}=\frac{\sum_{t=0}^{m} \Delta T^{t}}{\sum_{t=0}^{m}\left(\dot{q}^{t}\right)_{2}}
$$

Where $R_{c 1}$ and $R_{c 2}$ are the $\mathrm{R}_{\mathrm{c}^{-}}$values derived from (1), and based on the heat fluxes from indoor side and outdoor side respectively.

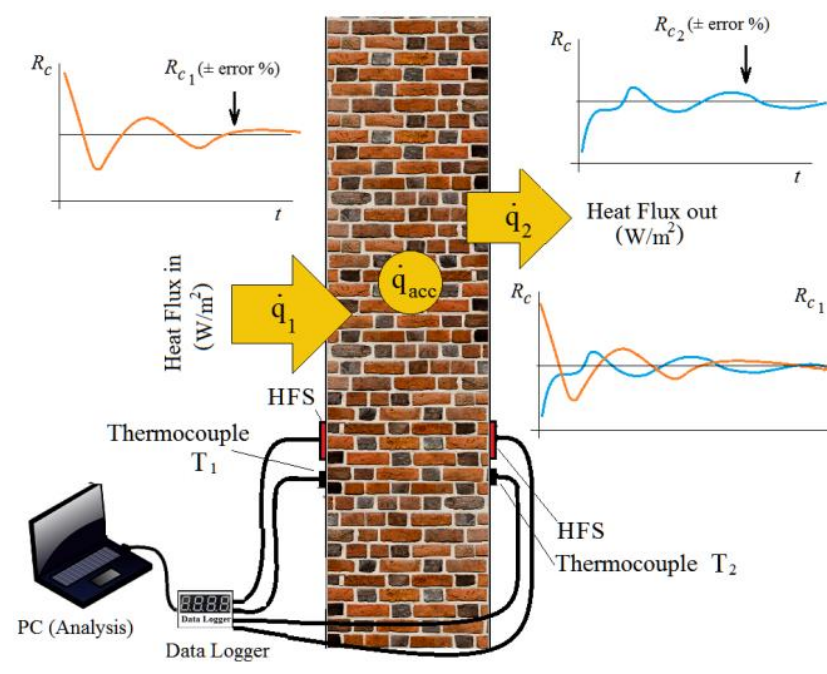

Fig. 1. The set-up of the proposed extension to the ISO 9869 average method: $\dot{q}_{a c c}$ is the heat accumulation rate.

Due to the different performances of the homogeneous and heterogeneous walls, a new value, the average of the two $\mathrm{R}_{\mathrm{c}}$-values is derived from the two heat fluxes and calculated as follows:

$R_{c-a v e}=\frac{\left(R_{c 1}+R_{c 2}\right)}{2}=\frac{1}{2}\left[\frac{\sum_{t=0}^{m} \Delta T^{t}}{\sum_{t=0}^{m}\left(\dot{q}^{t}\right)_{1}}+\frac{\sum_{t=0}^{m} \Delta T^{t}}{\sum_{t=0}^{m}\left(\dot{q}^{t}\right)_{2}}\right]$

The heat flux is measured at both sides separately, following the ISO 9869 [12] instructions, and the $\mathrm{R}_{\mathrm{c}^{-}}$ value curves are generated based on (1). Based on (4), the third curve is generated and referred to as $\mathrm{R}_{\mathrm{c} \text {-ave. }}$ The benefit of using this curve in certain cases is studied.

\section{Heat Transfer Simulations}

To study the effect of two-sided heat flux and $\mathrm{R}_{\mathrm{c}}$-value measurements following ISO 9869 [12] instructions, simulations have been carried out in COMSOL Multiphysics [22] to illustrate the thermal behavior of the walls. The details and the boundary conditions applied to these simulations are in accordance with ISO9869 [12]. Six typologies are studied in which homogeneous and heterogeneous walls are simulated under climatic conditions.

\subsection{Constructions and Typologies}

The homogeneous wall is a common brickwork wall. The heterogeneous walls include two two-layered insulated walls of brick and Polyurethane, once placed inside, and once outside. Similarly, two three-layered walls with insulation and air in the middle (symmetric) and a four-layered cavity wall are modelled. In Fig.2, the six types are shown.

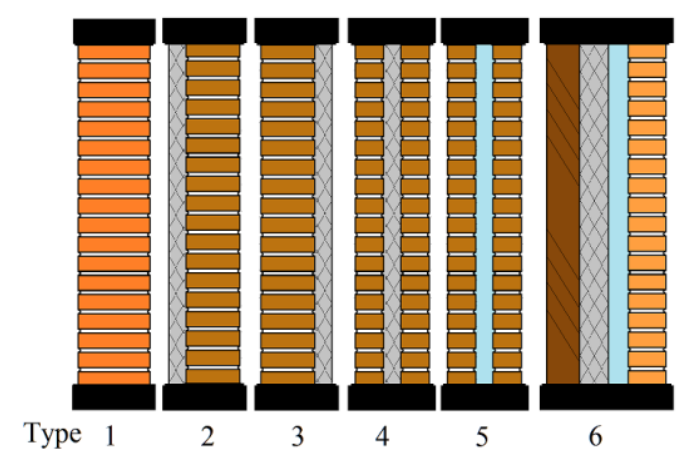

Fig. 2. The construction of the six typologies of simulated walls: single, double, triple, and four-layered façades

The details of the constructions of the simulated walls including their layers and materials as well as their theoretical $\mathrm{R}_{\mathrm{c}}$-values $\left(\mathrm{R}_{\mathrm{c}}{ }^{\text {th }}\right)$ are summarized in Table 1 .

Table 1. Construction and materials used in the simulated

\begin{tabular}{|c|c|c|c|}
\hline Type & Typology & Material(s) & $R_{c}^{t h}\left[\mathrm{~m}^{2} \mathrm{KW}^{-1}\right]$ \\
\hline 1 & Homogeneous & L1: Common Brick & 0.91 \\
\hline \multirow{2}{*}{2,3} & \multirow{2}{*}{$\begin{array}{l}\text { One-sided } \\
\text { Insulation }\end{array}$} & L1-L2: Brick & \multirow{2}{*}{4.00} \\
\hline & & L2-L1: Polyurethane & \\
\hline \multirow{2}{*}{4} & \multirow{2}{*}{$\begin{array}{c}\text { Middle } \\
\text { Insulation }\end{array}$} & L1-L3: Brick & \multirow{2}{*}{4.00} \\
\hline & & L2: Polyurethane & \\
\hline \multirow{2}{*}{5} & \multirow{2}{*}{$\begin{array}{c}\text { 3-Layered } \\
\text { Cavity Wall }\end{array}$} & L1-L3: Brick & \multirow{2}{*}{0.62} \\
\hline & & L2: Air Cavity & \\
\hline \multirow{4}{*}{6} & \multirow{4}{*}{$\begin{array}{l}\text { 4-Layered } \\
\text { Cavity Wall }\end{array}$} & L1: Facing Brick & \multirow{4}{*}{5.31} \\
\hline & & L2: Air Cavity & \\
\hline & & L3: Polyurethane & \\
\hline & & L4: Wood-Cement & \\
\hline
\end{tabular}
walls. The estimated $\mathrm{R}_{\mathrm{c}}$-value is based on thermal properties.

The thermal properties of the materials in each layer are given in Table 2. 
Table 2. Material properties of different layers in the simulated walls: thickness $(l)$, thermal conductivity $(k)$, density $(\rho)$, and specific heat capacity $(C)$ of each layer are presented.

\begin{tabular}{|c|c|c|c|c|c|}
\hline Type & Layer & $\begin{array}{c}\boldsymbol{l} \\
{[\mathbf{m}]}\end{array}$ & $\begin{array}{c}\boldsymbol{k} \\
{\left[\mathbf{W m}^{-\mathbf{1}} \mathbf{K}^{-\mathbf{1}}\right]}\end{array}$ & $\begin{array}{c}\boldsymbol{\rho} \\
{\left[\mathbf{k g m}^{-\mathbf{3}}\right]}\end{array}$ & $\begin{array}{c}\boldsymbol{C} \\
{\left[\mathbf{J k g}^{-\mathbf{1}} \mathbf{K}^{-\mathbf{1}}\right]}\end{array}$ \\
\hline $\mathbf{1}$ & $\mathrm{L} 1$ & 0.55 & 0.6 & 2400 & 840 \\
\hline \multirow{2}{*}{$\mathbf{2 , 3}$} & L1-L2 & 0.2 & 0.9 & 2000 & 840 \\
\cline { 2 - 6 } & L2-L1 & 0.08 & 0.021 & 35 & 1320 \\
\hline \multirow{2}{*}{$\mathbf{4}$} & L1,L3 & 0.2 & 0.9 & 2000 & 840 \\
\cline { 2 - 6 } & L2 & 0.08 & 0.021 & 35 & 1320 \\
\hline \multirow{2}{*}{5} & L1,L3 & 0.2 & 0.9 & 2000 & 840 \\
\cline { 2 - 6 } & L2 & 0.04 & $k=k(T)$ & $\rho=\rho(T)$ & $C=C(T)$ \\
\hline \multirow{4}{*}{$\mathbf{6}$} & L1 & 0.10 & 0.900 & 2087 & 87 \\
\cline { 2 - 6 } & L2 & 0.04 & $k=k(T)$ & $\rho=\rho(T)$ & $C=C(T)$ \\
\cline { 2 - 6 } & L3 & 0.10 & 0.021 & 35 & 1320 \\
\cline { 2 - 6 } & L4 & 0.09 & 0.350 & 1250 & 1470 \\
\hline
\end{tabular}

\subsection{Boundary Conditions}

The walls' boundary conditions include convective heat transfer coefficient $25 \mathrm{Wm}^{-2} \mathrm{~K}^{-1}$ for the outdoor air and $7.5 \mathrm{Wm}^{-2} \mathrm{~K}^{-1}$ for the indoor air. The Infrared radiation is lumped in forced and natural convection heat transfer phenomena. The lateral sides are insulated and the initial condition is an average temperature of $291 \mathrm{~K}$ for all solid domains. In accordance with the instructions of ISO 9869 [12] (protecting the wall's exterior surface via screening), solar radiation, rain, snow, and wind are excluded. The effect of solar radiation is investigated in [21]. In Fig. 3, the boundary conditions applied to the walls, exposed to heat convection (surface resistance $\alpha$ ) with indoor and outdoor air (temperature $\mathrm{T}^{\infty}$ ) are shown.

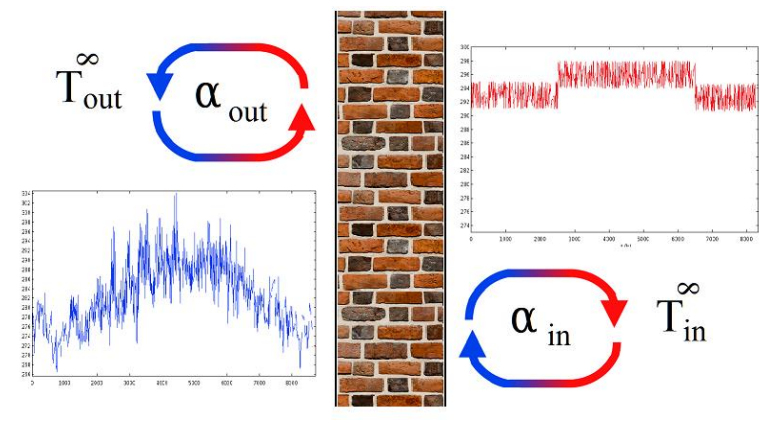

Fig. 3. Boundary conditions applied to the simulations: indoor and outdoor air temperatures and convective resistances

The air temperature profiles include outdoor temperature from reference climate year deBilt 64-65 (a typical climate year in the Netherlands) and the indoor air temperature of $293 \mathrm{~K}$ (heating season) and $296 \mathrm{~K}$ (cooling season) with a white noise of $\pm 2 \mathrm{~K}$ magnitude.

\section{Results and Discussion}

The results of the simulations are presented in this section. The first result refers to the homogeneous wall. In addition to the high thermal mass in this construction, the homogeneity of this construction results in a quite stable symmetrical heat flux profile at two sides and therefore, symmetrical curves of $\mathrm{R}_{\mathrm{c}}$-values for inside and outside surfaces. Accordingly, the average of the two profiles, as derived in (4), converges much more quickly to an accurate $\mathrm{R}_{\mathrm{c}}$-value. This phenomenon is shown in Fig 4. In all figures red and blue curves refer to $R_{c}$ values derived from indoor and outdoor heat fluxes respectively. The dashed black curve is the average of the two. Curves Rc-in and Rc-out are $R_{c 1}$ and $R_{c 2}$ in (3).

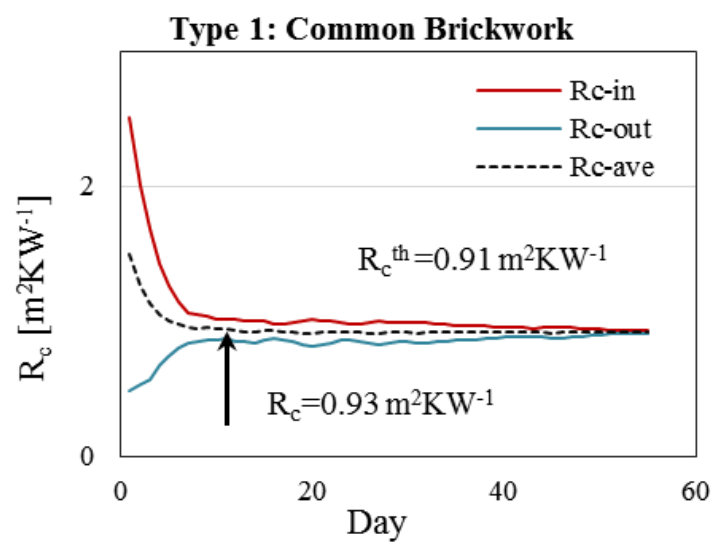

Fig. 4. The simulation results for the homogeneous wall

Note that in case of a thin homogeneous wall, the chance of finding symmetric profiles is lower. In such cases, with no problem of the measurement duration, the indoor

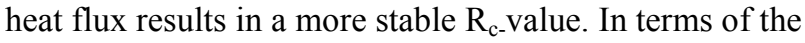
thermal resistance measurement, the behavior of the common brickwork wall (Fig 4) is similar to the ones of red brick and concrete, reported in [21].

After the homogeneous wall, the heterogeneous walls are modelled [21]. Two two-layered walls of brick and insulation in which the insulation is once placed outside (type 2) and once inside (type 3) are presented. In Fig. 5 and Fig. 6, the results of these two cases are depicted.

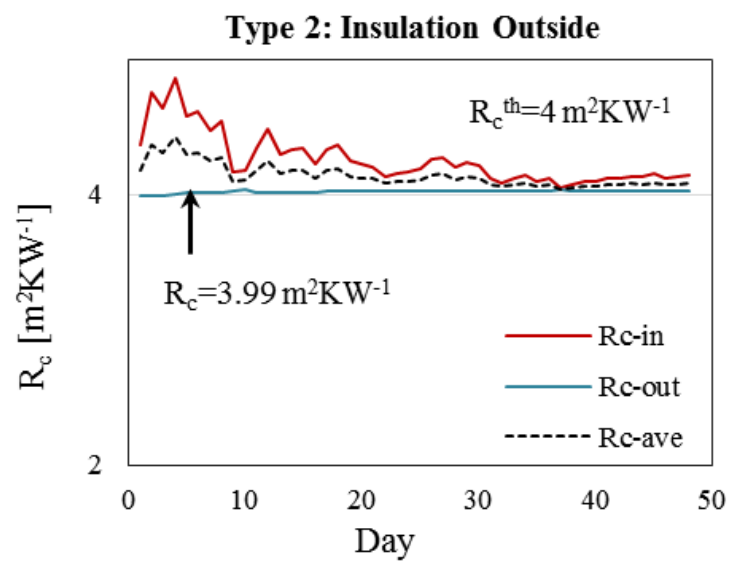

Fig. 5. The simulation results of the two-layered wall with insulation placed on the outside surface

As seen in Fig. 5, in contrast with conventional suggestions (measuring the heat flux at indoor side), the results based on outdoor heat flux measurements are 
more stable and therefore lead to a quicker achievement of the $\mathrm{R}_{\mathrm{c}}$-value.

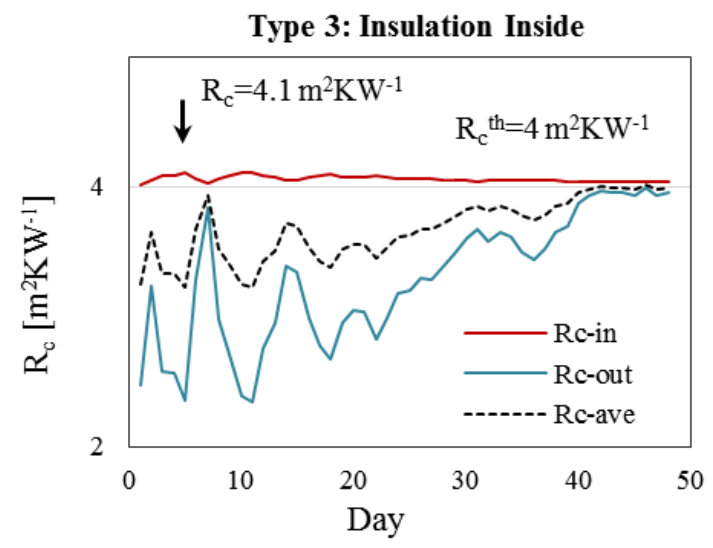

Fig. 6. The results of the simulation of the two-layered wall when insulation placed on the inside surface

The case of placing the insulation at the indoor side of the wall (Fig. 6) results in an opposite behavior. The indoor heat flux results much more quickly to the $\mathrm{R}_{\mathrm{c}}$ value.

As seen in Figs. 5 and 6, the location of the insulation layer has shown a significant influence on the heat flux and therefore, the results of the $\mathrm{R}_{\mathrm{c}}$-value convergence. The stability of the heat flux profile depends not only on the air temperature profile, but also the heat conduction and accumulation through the solid domain. This effect in the modelled construction can become dominant to the air temperature fluctuations and therefore determining the event of $\mathrm{R}_{\mathrm{c}}$-value curves' convergence at either side. Note that other disturbances such as solar radiation are already neglected as stated in the standard method.

Once the insulation (and therefore the stability effect of heat conduction and accumulation) is put in the middle, the effect is divided between the two halves of the wall, letting the air temperature profile determine the event of $\mathrm{R}_{\mathrm{c}}$-value convergence. In Fig. 7, the results of the same two-component wall are shown when the insulation layer is in the middle.

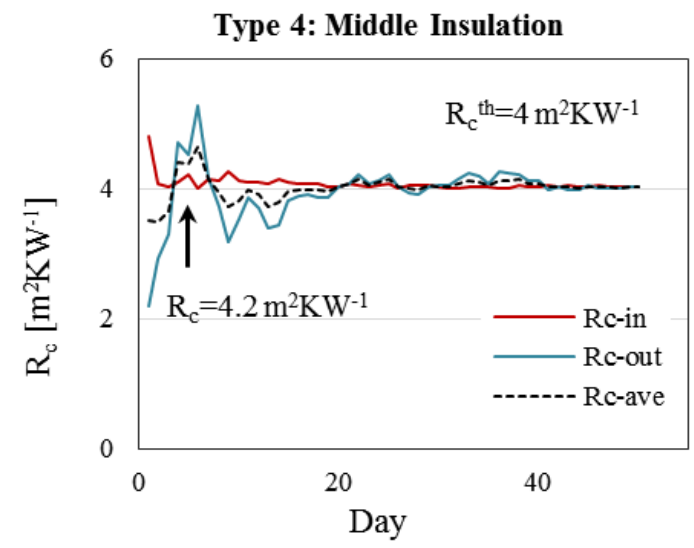

Fig. 7. The simulation results of the two-layered wall with insulation placed in the middle (type 4)
In Fig. 4, resulting from the air temperature fluctuation at the outdoor surface, the heat flux at this layer is less stable than the one of indoor surface. This leads to the quicker convergence of the Rc-in graph than the one of the Rc-out.

As seen from Figs 5, 6, and 7, as the convergence time of the $\mathrm{R}_{\mathrm{c}}$-value is a function of the heat flux stability, in a two-component wall with a strong insulation layer, is a function of the location of the insulation. In a twocomponent wall of thickness $\mathrm{L}$, as the location of the insulation changes from indoor to outdoor ( 0 to $\mathrm{L})$, the required measurement time for Rc-in increases as the one of Rc-out decreases. This effect is shown in Fig. 8, for the simulated walls (types 2, 3, and 4).

As the construction of the walls can be unknown, the use of two heat flux meters at two sides will help in finding the $\mathrm{R}_{\mathrm{c}}$-value much quicker in any case.

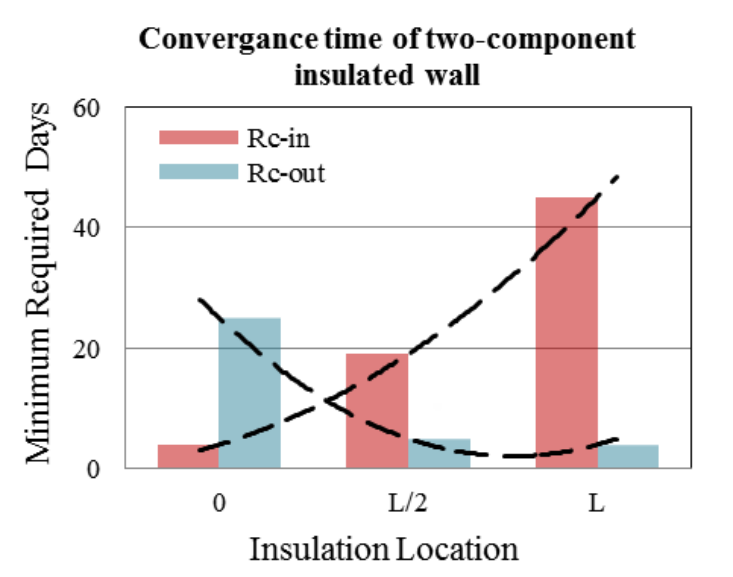

Fig. 8. The correlation between the location of the insulation and the convergence time of the $\mathrm{R}_{\mathrm{c}}$-value graph based on heat flux measurements at either of the sides (indoor and outdoor)

Being very popular for the performance, the cavity walls are widely used in the buildings. In Fig. 9, the result of the simulation of a symmetrical three-layered cavity wall is presented. As the insulation provided by the cavity is low, this case should not be confused with type 4 where instead of the air, Polyurethane is in the middle.

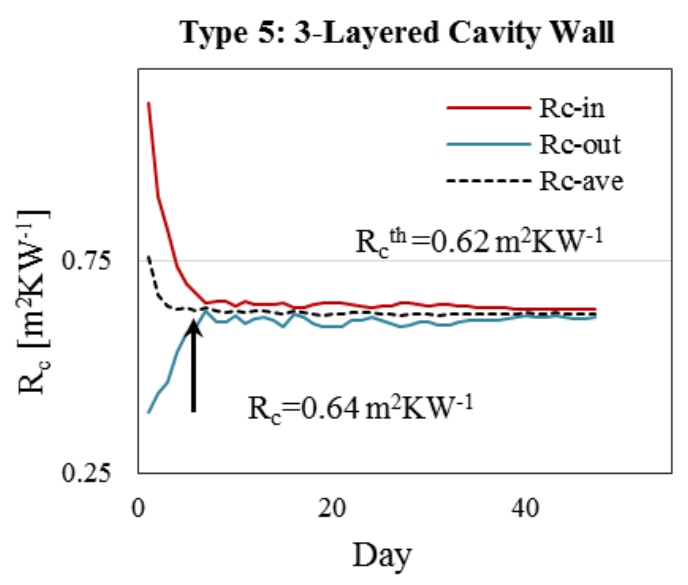

Fig. 9. The simulation results of the symmetrical (3-layered) cavity wall 
As seen in this typology, the performance is similar to the one of homogeneous walls. Accordingly, the Rc-ave curve converges much more quickly to the correct value.

Finally, the results of a four-layered cavity wall with cavity placed closer to the outdoor surface are presented in Fig. 10.

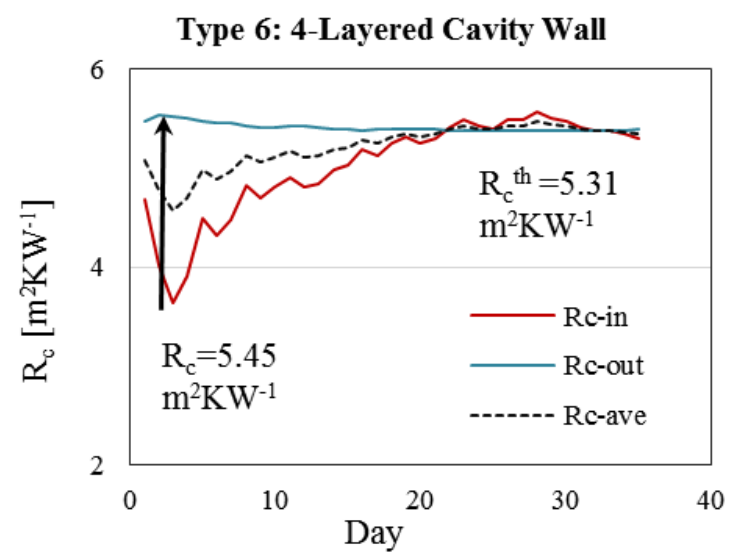

Fig. 10. The results of the simulations: four-layered cavity wall with cavity placed closer the outside surface.

As seen in the graphs, similar to type 2, in the fourlayered cavity wall, the $\mathrm{R}_{\mathrm{c}}$-value based on the exterior side's heat flux measurements (Rc-out) converges much quicker to the correct $\mathrm{R}_{\mathrm{c}}$-value.

\section{Conclusion}

An extension [21] to the Average method of ISO 9869 [12] standard was investigated and further studied. From the results of the heavy-constructed common brickwork homogeneous wall, it is concluded that in heavy homogeneous constructions, the average of the two $R_{c}-$ values, based on indoor and outdoor heat fluxes, converges much earlier to the correct value. Therefore, it is beneficial to use the second heat flux meter and use the average to shorten the measurement period. The same conclusion can be drawn for the case of symmetric walls, when the middle layer does not have a much different $\mathrm{R}_{\mathrm{c}}$-value. Accordingly, the 3-layered cavity wall (type 5) has shown a similar behavior to the homogeneous walls where taking the average value of the two $\mathrm{R}_{\mathrm{c}}$-values of indoor and outdoor heat fluxes are of great benefit in terms of time efficiency.

The case of a heavy insulation in the middle (type 4) shows the same behavior as a light construction as it divides the wall into two individual light constructions whose heat fluxes are mainly affected by the heat convection (air temperature profile) and therefore, letting the indoor heat flux result in a quicker achievement of the $\mathrm{R}_{\mathrm{c}}$-value. Analyzing the results of this type next to the results of the two-component walls with brick and polyurethane has shown the effect of the location of the insulation on the speed of the convergence of the $R_{c}$ value graph. The closer the insulation gets to the outdoor surface, the quicker the outdoor heat flux $R_{c}$-value graph converges to the correct value, and vice versa. In case the insulation layer is placed at the outdoor surface (type 2 ), it is much quicker to use the outdoor heat flux to derive the $\mathrm{R}_{\mathrm{c}}$-value whereas for the insulation at the indoor surface (type 3 ) it is the opposite. The fourlayered asymmetric cavity wall (type 6) has shown a similar behavior as type 2 as the insulation was closer to the outdoor surface. As the construction of the walls are generally unknown, it is always of great necessity to use two heat flux meters at both sides of the wall and to derive and generate the tree $\mathrm{R}_{\mathrm{c}}$-value curves, the ones based on outdoor and indoor heat fluxes and the average of the two. Monitoring the three curves leads to finding the quickest converging curve and therefore the correct $\mathrm{R}_{\mathrm{c}}$-value in a much shorter time.

\section{References}

1. Deconinck, A.-H. and S. Roels, Comparison of characterisation methods determining the thermal resistance of building components from onsite measurements. Energy and Buildings, 2016. 130: p. 309-320.

2. Deconinck, A.-H. and S. Roels, Is stochastic greybox modelling suited for physical properties estimation of building components from on-site measurements? Journal of Building Physics, 2017. 40(5): p. 444-471.

3. Deconinck, A.-H. and S. Roels, The as-built thermal quality of building components: characterising non-stationary phenomena through inverse modelling. Energy Procedia, 2017. 132: p. 351-356.

4. Gori, V., V. Marincioni, P. Biddulph, and C.A. Elwell, Inferring the thermal resistance and effective thermal mass distribution of a wall from in situ measurements to characterise heat transfer at both the interior and exterior surfaces. Energy and Buildings, 2017. 135: p. 398-409.

5. Martín, K., I. Flores, C. Escudero, A. Apaolaza, and J.M. Sala, Methodology for the calculation of response factors through experimental tests and validation with simulation. Energy and Buildings, 2010. 42(4): p. 461-467.

6. Sala, J.M., A. Urresti, K. Martín, I. Flores, and A. Apaolaza, Static and dynamic thermal characterisation of a hollow brick wall: Tests and numerical analysis. Energy and Buildings, 2008. 40(8): p. 1513-1520.

7. Yesilata, B. and P. Turgut, A simple dynamic measurement technique for comparing thermal insulation performances of anisotropic building materials. Energy and Buildings, 2007. 39(9): p. 1027-1034.

8. ISO, B., 8990: 1996, Thermal insulation. Determination of steady-state thermal transmission properties. Calibrated and guarded hot box, BSI, ISBN 0, 1996. 580(26826): p. 8.

9. Robinson, A.J., F.J. Lesage, A. Reilly, G. McGranaghan, G. Byrne, R. O'Hegarty, and O. Kinnane, A new transient method for determining 
thermal properties of wall sections. Energy and Buildings, 2017. 142: p. 139-146.

10. ASTM, C., 1046-95 (Reapproved 2001): Standard practice for in-situ measurement of heat flux and temperature on building envelope components. Annual Book of ASTM Standards, 2001. 4.

11. ASTM, C., 1155-95 (Reapproved 2001): Standard practice for determining thermal resistance of building envelope components from the in-situ data. Annual Book of ASTM Standards, 2001. 4.

12. ISO, I., 9869: Thermal insulation-Building elements-In-situ measurements of thermal resistance and thermal transmittance. International Organization for Standardization, Geneva, 2014.

13. Atsonios, I.A., I.D. Mandilaras, D.A. Kontogeorgos, and M.A. Founti, A comparative assessment of the standardized methods for the insitu measurement of the thermal resistance of building walls. Energy and Buildings, 2017. 154: p. 198-206.

14. Biddulph, P., V. Gori, C.A. Elwell, C. Scott, C. Rye, R. Lowe, and T. Oreszczyn, Inferring the thermal resistance and effective thermal mass of a wall using frequent temperature and heat flux measurements. Energy and Buildings, 2014. 78: p. 10-16.

15. Rasooli, A., L. Itard, and C.I. Ferreira, A response factor-based method for the rapid in-situ determination of wall's thermal resistance in existing buildings. Energy and Buildings, 2016. 119: p. 51-61.

16. Cesaratto, P.G., M. De Carli, and S. Marinetti, Effect of different parameters on the in situ thermal conductance evaluation. Energy and Buildings, 2011. 43(7): p. 1792-1801.

17. Wang, F., D. Wang, X. Wang, and J. Yao, A data analysis method for detecting wall thermal resistance considering wind velocity in situ. Energy and Buildings, 2010. 42(10): p. 1647-1653.

18. Baker, P., Technical Paper 10: U-values and traditional buildings-In situ measurements and their comparisons to calculated values. 2011.

19. Ahmad, A., M. Maslehuddin, and L.M. AlHadhrami, In situ measurement of thermal transmittance and thermal resistance of hollow reinforced precast concrete walls. Energy and Buildings, 2014. 84: p. 132-141.

20. Baker, P., Technical Paper 2: In situ U-value measurements in traditional buildings-preliminary results. 2008.

21. Rasooli, A. and L. Itard, In-situ characterization of walls' thermal resistance: An extension to the ISO 9869 standard method. Energy and Buildings, 2018. 179: p. 374-383.

22. COMSOL Multiphysics ${ }^{\circledR} \quad$ v. 5.3.a www.comsol.com. COMSOL AB, S., Sweden. 